\title{
Incidence and outcome for patients with occult lymph node involvement in T1 and T2 oral squamous cell carcinoma: a prospective study
}

\author{
Thomas Mücke ${ }^{1,2^{*}}$, David A Mitchell ${ }^{2}$, Stefan Wagenpfeil ${ }^{3}$, Lucas M Ritschl ${ }^{1}$, Klaus-Dietrich Wolff ${ }^{1}$ \\ and Anastasios Kanatas ${ }^{2}$
}

\begin{abstract}
Background: The evidence base to inform the decision making process in patients with early stage oral cancer and a clinical and radiological NO neck remains insufficient to answer the question when it is safe to "watch and wait" and when to proceed with a selective neck dissection.

Methods: A total of 327 consecutive cases of histopathologically staged $T_{1-2}, N_{0-1}$ and $M_{0}$, but clinically $N_{0}$, squamous cell carcinoma of the tongue were prospectively analysed. Univariate and multivariate analyses were used for statistical analysis and are represented as Kaplan-Meier analyses or Cox proportional hazard regression analysis.
\end{abstract}

Results: In 61 patients (18.65\%) lymph node involvement was found in the histopathological processing. The mean survival of all patients was $73.3 \pm 48.6$ months. The 2-year and 5 -year overall survival rates of all patients were $87.5 \%$ and $68.4 \%$, respectively. The 2-year and 5-year survival rates for stage $N_{0}$ were $89.1 \%$ and $70.7 \%$ compared to $83.3 \%$ and $62.9 \%$ in $\mathrm{N}_{1}$ situations. The 2-year and 5 -year survival rates for stage $\mathrm{T}_{1}$ were $87.9 \%$ and $73.6 \%$ compared to $87.2 \%$ and $65.3 \%$ in stage $T_{2}$, respectively. The time to recurrence in stage $N_{0}$ was $35.1 \pm 30.5$ months compared to $25.63 \pm 24.6$ months in cases with $N_{1}$ disease. Stage $T_{1}$ was associated with a time to recurrence of $38.1 \pm$ 33.9 months compared with $27.2 \pm 22.7$ months in patients classified $T_{2}$.

Variables found to be strongly associated with survival in the univariate analysis included older age, higher tumour and $\mathrm{N}$ stage, and grading. Age, tumour stage $(\mathrm{p}=0.011,95 \% \mathrm{Cl}, 1.09$ to 2.0$)$, nodal stage $(\mathrm{p}=0.038,95 \% \mathrm{Cl}, 1.02$ to 2.07), and recurrence were independently and significantly associated with survival in the multivariate analysis.

Conclusions: This confirms a high overall disease free survival for patients with $\mathrm{T} 1$ and NO treated with single modality surgery and in common with the literature confirms the poor impact on prognosis of the $\mathrm{N}$ positive neck.

Keywords: Oral cancer, Outcome, Lymph node metastasis, Neck dissection

\section{Background}

The incidence of pathologically positive lymph nodes in the clinically and radiologically negative neck (NO) in $\mathrm{T}_{1}$ and $\mathrm{T}_{2}$ squamous cell carcinomas (SCC) of the oral cavity remains controversial. A prospective randomised trial

\footnotetext{
* Correspondence: th.mucke@gmx.de

${ }^{1}$ Department of Oral and Maxillofacial Surgery, Technische Universität München, Klinikum Rechts der Isar, Ismaninger Str. 22, 81675 Munich, Germany

${ }^{2}$ Department of Oral and Maxillofacial Surgery, Oral and Facial Specialties Department, Mid Yorkshire Hospitals NHS Trust, Aberford Road, WF1 4DG West Yorks, UK

Full list of author information is available at the end of the article
}

is attempting to answer the question of when it is in the best interests of the patient to carry out elective neck dissection (SEND). Several single centre audits have demonstrated an incidence of around $30 \%$ positive cervical nodes in clinically and radiologically undetected cases with T2 tongue and floor of mouth squamous cancer. Belief that only thin T2 and T1 SCC should not undergo neck dissection (patient factors permitting) is so strong that recruitment to the SEND study has been slow. Surgery with or without radiation and chemotherapy is the established curative treatment of SCC [1]. Treatment of locally advanced SCC within an isolated 
organ of the oral cavity is recognised as requiring multimodal treatment approaches including surgery and radiotherapy with or without chemotherapy [2]. Although ablative surgery with or without reconstruction is an established therapy for small tumours staged at $\mathrm{T}_{1}$ and $\mathrm{T}_{2}$ created controversies exists around the role of neck dissection. Controversy also exists with radiation therapy which is a single use treatment with lifelong post treatment morbidity [3]. The management decision around small stage T1 and T2 SCC particularly thin tumours centers around either a wait-and-see policy or a selective neck dissection of the ipsilateral lymph nodes of level I-IV, which logically should be bilateral in midline lesions $[4,5]$.

The purpose of the present study was to investigate the oncologic results and role of primary surgical treatment for clinically early-stage SCC. The incidence of lymph node involvement and its role in overall survival was further investigated.

\section{Methods \\ Eligibility}

Any patient who had histologically confirmed invasive SCC of the tongue histopathologically staged $\mathrm{T}_{1-2}, \mathrm{~N}_{0-1}$ and $M_{0}$ was eligible. Exclusion criteria included previous malignancy at the oral cavity or positive resection margins.

\section{Ethics and consent}

Every patient gave an informed consent to participate in clinical studies regarding the analyses of survival and outcome of their treatments. Due to the informed consent already given by patients to participate in studies and willing to perform the required medical care an exemption from requiring ethics approval was granted by the Ethical Committee of the University of Munich.

\section{Staging}

All patients underwent incisional biopsy, computed tomography (CT) or magnetic resonance imaging (MRI), skeletal scintigraphic surveys, sonography, and thoracic $\mathrm{x}$-ray. Lymph nodes of more than $1 \mathrm{~cm}$ with a rounded configuration were regarded as probably involved by imaging criteria. In addition, clinical assessment was controlled by CT and/or MRI scans as well as sonography examination. All diagnostics were performed by an expert radiologist and individual cTNM was confirmed by an interdisciplinary tumour board including specialists from radiology, oral and maxillofacial surgery, ear nose and throat surgeons, oncology, radiation therapy, and nuclear medicine. Postoperative histopathological assessment by the pathologists was used as the diagnostic gold standard, retrospectively.

\section{Surgery}

As part of the staging process all patients underwent histological confirmation of the diagnosis. The extent of neck dissection was performed uni- or bilaterally in level I-III of the neck, depended on the location of metastases intraoperatively [1]. The tumour resection was performed surgically according to current guidelines and as described before followed by microvascular reconstruction [6].

\section{Follow-up}

After surgery, patients were assessed every 3 months for the first 2 years, every 6 months for another 2 years, and every year thereafter. Investigations to detect recurrence were done by clinical inspection and yearly CT routinely.

\section{Data analysis}

Data of the study were prospectively collected in one single department and analysed. Overall survival in months and 5-year overall survival were used as dependent variables. Associations of possible predictor variables with the dependent variable, survival, were determined using the Kaplan-Meier estimator, univariate log-rank test, and Cox proportional hazards regression models. Multiple Cox proportional hazards regression models were conducted to explore the relationship between neck involvement and survival, as were variables shown in the literature to be associated with survival.

Measurements of tumour related differences were compared using the non-parametric Fisher-test, as appropriate. The Kaplan-Meier method was used to plot survival curves for each putative binary prognostic factor. P-values are two-sided and subject to a global significance level of 0.05 . The data were analysed with the "Statistical Package for the Social Sciences" (SPSS for Windows, release 21, 2013, SPSS Inc, Chicago, IL, USA).

\section{Results}

\section{General characteristics}

From 1992 to 2008, of the 327 patients matching the criteria were treated. Among these, 266 patients did not show lymph node involvement histopathologically and in 61 patients $(18.65 \%)$ lymph node involvement was found. The median follow-up was 66 months (range 1-192). Patient demographic, clinical, and tumour characteristics are summarized in Table 1.

\section{Outcome}

The mean survival of all patients was $73.3 \pm 48.6$ months. The 2-year overall survival rate of all patients was 87.5\%. 5-year overall survival rate of all patients was $68.4 \%$. Among the patients with tumour stages classified as $\mathrm{T}_{1}$ the overall survival rates were $87.9 \%$ and $73.6 \%$ at 2 and 5 years, respectively. The overall survivals in $\mathrm{T}_{2}$ 
Table 1 Demographic, Clinical, and Cancer Characteristics of all patients, with and without lymph node involvement

\begin{tabular}{|c|c|c|c|c|c|c|c|}
\hline \multirow[b]{2}{*}{ Characteristic } & \multicolumn{2}{|c|}{ All patients } & \multicolumn{2}{|c|}{ Without lymph node involvement } & \multicolumn{2}{|c|}{ With lymph node involvement } & \multirow[t]{2}{*}{ p-value } \\
\hline & No. & $\%$ & No. & $\%$ & No. & $\%$ & \\
\hline Mean age (years) & 60.6 & & 60.25 & & 62.28 & & \\
\hline SD & 12.45 & & 12.45 & & 12.39 & & \\
\hline Range & $30-91$ & & $30-91$ & & $30-91$ & & \\
\hline \multicolumn{8}{|l|}{ Sex } \\
\hline Woman & 105 & 32.1 & 82 & 78.1 & 23 & 21.9 & \multirow{2}{*}{0.215} \\
\hline Men & 222 & 67.9 & 184 & 82.9 & 38 & 17.1 & \\
\hline \multicolumn{8}{|l|}{ Performance status } \\
\hline Dead & 129 & 39.4 & 98 & 76.0 & 31 & 24.0 & \multirow{2}{*}{0.074} \\
\hline Alive & 198 & 60.6 & 168 & 84.8 & 30 & 15.2 & \\
\hline \multicolumn{8}{|l|}{ Tumor stage } \\
\hline 1 & 193 & 59.0 & 175 & 90.6 & 18 & 9.3 & \multirow{2}{*}{$<0.001$} \\
\hline 2 & 134 & 41.0 & 91 & 67.9 & 43 & 32.1 & \\
\hline \multicolumn{8}{|l|}{ N stage } \\
\hline 0 & 266 & 81.3 & 266 & 100 & & & \\
\hline 1 & 61 & 18.7 & & & 61 & 100 & \\
\hline \multicolumn{8}{|l|}{ Tumor grade } \\
\hline 1 & 52 & 15.9 & 48 & 92.3 & 4 & 7.7 & \multirow{3}{*}{$<0.001$} \\
\hline 2 & 236 & 72.2 & 198 & 83.9 & 38 & 16.1 & \\
\hline 3 & 39 & 11.9 & 20 & 51.3 & 19 & 48.7 & \\
\hline \multicolumn{8}{|l|}{ Recurrence } \\
\hline 0 & 257 & 78.6 & 214 & 83.3 & 43 & 16.7 & \multirow{2}{*}{0.083} \\
\hline 1 & 70 & 21.4 & 52 & 74.3 & 18 & 25.7 & \\
\hline
\end{tabular}

Abbreviations: ${ }^{*} \mathrm{p}<0.05$.

tumour stages were $87.2 \%$ and $65.3 \%$ at 2 and 5 years, respectively. In patients without lymph node involvement the 2-year overall survival rate was $89.1 \%$ compared to $83.3 \%$ of patient with stage $\mathrm{N}_{1}$. The corresponding 5 -year overall survival rates were $70.7 \%$ for patients without and $62.9 \%$ for patients with lymph node involvement at stage $\mathrm{N}_{1}$. At the time of analysis, $198(60.6 \%)$ patients were alive and 129 (39.4\%) had died. Subdividing patients who were classified as tumour stage $\mathrm{T}_{1}$, the mean survival was $74.86 \pm 49.3$ months compared to $71.1 \pm 47.48$ in patients classified as $T_{2}$; patients without lymph node involvement had a mean survival of $74.17 \pm 49.0$ months compared to $69.55 \pm 46.7$ months in patients staged as $\mathrm{N}_{1}$. The time of recurrence was $38.1 \pm 33.9$ months in patients classified at tumour stage $\mathrm{T}_{1}$ compared with $27.2 \pm 22.7$ months in patients classified $\mathrm{T}_{2}$. In patients without lymph node involvement the time of recurrence was $35.1 \pm 30.5$ months compared to $25.63 \pm 24.6$ months in patients with $\mathrm{N}_{1}$ disease. A total of 70 patients (21.4\%) developed recurrences, 52 patients without lymph node involvement and 18 with lymph node involvement (Table 1). In relation to all patients without lymph node involvement $19.5 \%$ developed recurrences (52/266), whereas $26.8 \%$ of patients $(18 / 61)$ with lymph node involvement developed recurrences.

\section{Univariate analysis}

Variables found to be strongly associated with survival in the univariate analysis included age, tumour and $\mathrm{N}$ stage, and grading. The higher the age, tumour and $\mathrm{N}$ stage, as well as the grading of the tumour, the more negative was the effect on survival probability. There was no relationship between survival and recurrence or the sex of patient (Table 2). Kaplan-Meier analyses for each variable significantly influencing survival are presented in Figures 1, 2, and 3.

\section{Multivariate analysis}

Cox proportional hazard regression model analysis was conducted controlling for age, tumour stage, nodal stage, tumour grade, and recurrence. Sex was not associated with survival in the univariate model and thus not included in the multivariate analysis. Recurrence was also included into the analysis as it has been reported to be a significant factor associated with survival in the literature. 
Table 2 Univariate Analysis for the factors influencing overall survival ( $N=327: 129$ death events and 198 censored)

\begin{tabular}{llll}
\hline Variable & Hazard ratio & $\mathbf{9 5 \%} \mathbf{C l}$ & $\mathbf{p}$ \\
\hline Age & 1.03 & 1.02 to 1.03 & $<0.0001^{*}$ \\
Tumor stage & 1.252 & 1.16 to 1.35 & $=0.01^{*}$ \\
N stage & 1.60 & 1.44 to 1.77 & $=0.049^{*}$ \\
Tumor grade & 1.46 & 1.21 to 1.76 & $=0.002^{*}$ \\
Sex & 1.02 & 0.83 to 1.25 & 0.365 \\
Recurrence & 1.23 & 1.00 to 1.52 & 0.911 \\
\hline
\end{tabular}

Abbreviations: * $\mathrm{p}<0.05$.

Age, tumour stage ( $\mathrm{p}=0.011,95 \% \mathrm{CI}, 1.09$ to 2.0 ), nodal stage ( $\mathrm{p}=0.038,95 \% \mathrm{CI}, 1.02$ to 2.07 ), and recurrence were independently and significantly associated with survival (Table 3). The higher the age, tumour, and nodal stage, the more negative was the effect on survival probability.

\section{Discussion}

In this study we reported the incidence of clinical occult metastases in patients with $\mathrm{T}_{1}$ and $\mathrm{T}_{2}$ tongue squamous cell carcinomas. Our outcomes have been presented followed by conclusions based on our experience.

Our overall survival rates of our population of patients are comparable with those from other studies and much better than the frequently quoted crude overall survival from oral cancer of 56\% [7-9]. Therefore our results may be extrapolated to patients from other countries with

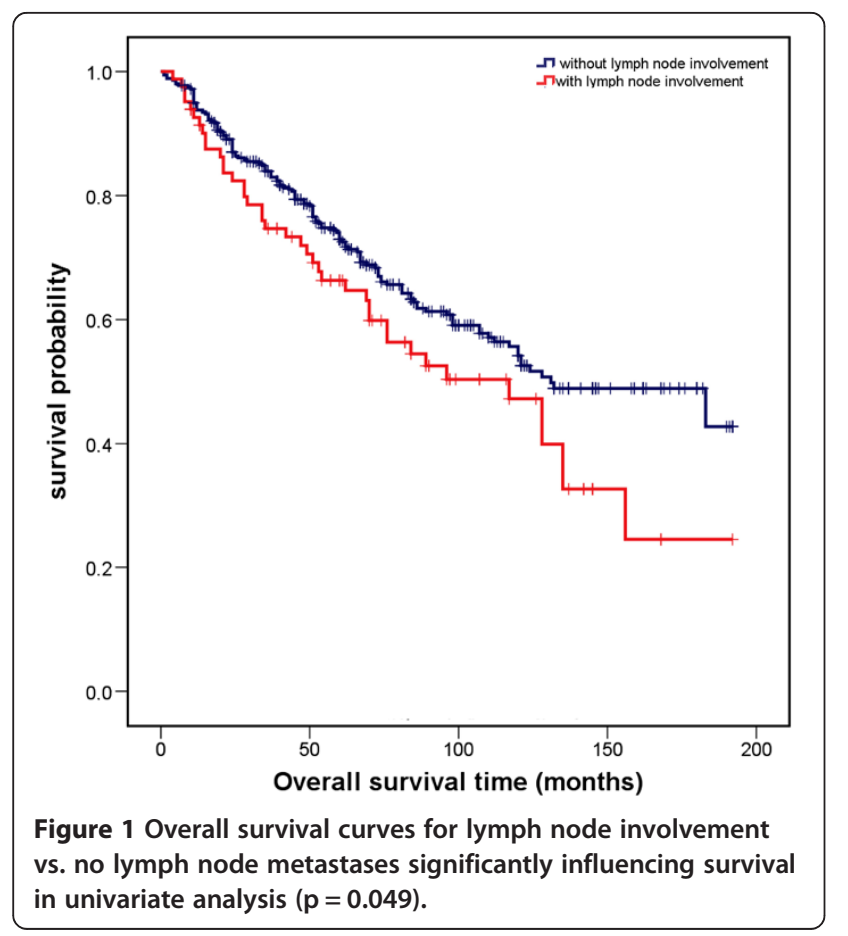

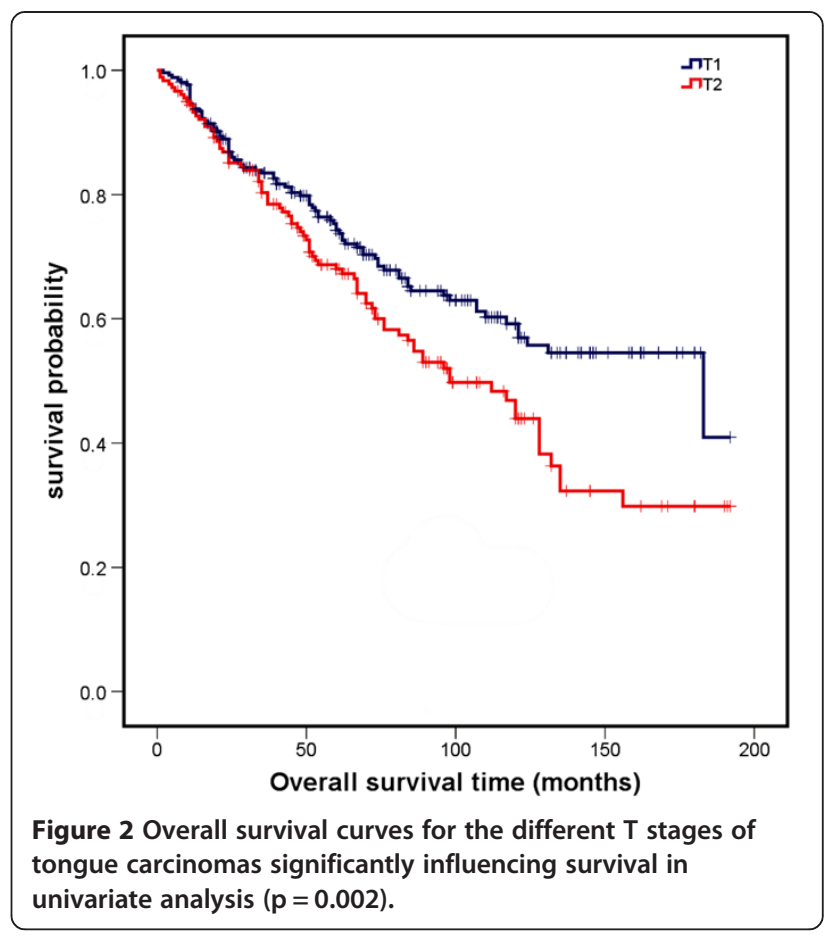

similar staging. Management of the $\mathrm{N}_{0}$ neck in head and neck squamous cell carcinoma is an important issue for the head and neck surgeon. In patients with head and neck cancer, the presence of lymph nodes metastases is the most important prognostic factor [10]. The management of patients with clinically negative nodes $\left(\mathrm{N}_{0}\right)$ with early tongue cancer is controversial. There are available

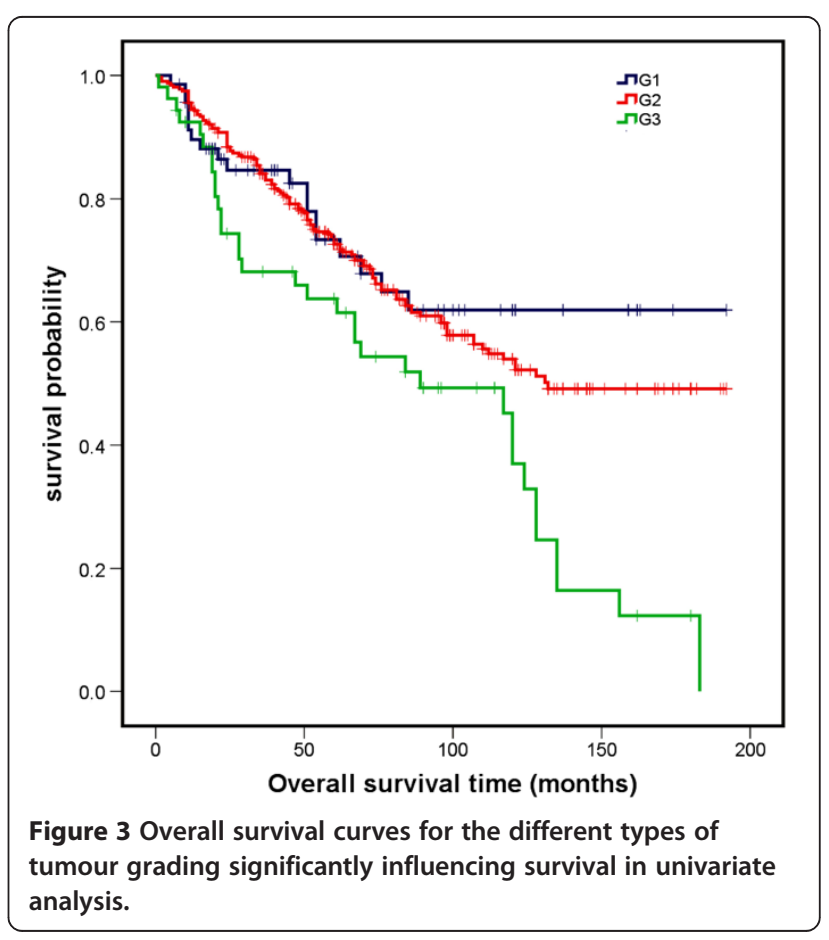


Table 3 Multivariate Analysis for the factors influencing overall survival ( $N=327: 129$ death events and 198 censored)

\begin{tabular}{llll}
\hline Variable & Hazard ratio & $\mathbf{9 5 \%} \mathbf{C l}$ & $\mathbf{p}$ \\
\hline Age & 1.04 & 1.02 to 1.05 & $<0.0001^{*}$ \\
Sex & 1.11 & 0.73 to 1.71 & $=0.622$ \\
Tumor stage & 1.48 & 1.09 to 2.0 & $=0.011^{*}$ \\
N stage & 1.68 & 1.04 to 2.74 & $=0.034^{*}$ \\
Recurrence & 1.79 & 1.09 to 2.98 & $=0.022^{*}$ \\
Tumor grade & 1.54 & 1.16 to 2.05 & $=0.003^{*}$ \\
\hline
\end{tabular}

Abbreviations: ${ }^{*} \mathrm{p}<0.05$

papers in the literature but the results of these have not provided a satisfactory answer to the controversy [11-14]. There is a single randomised controlled trial attempting to provide an evidence base for guidance on the definition of a threshold of risk over which a neck dissection is indicated. It is widely believed that tumour thickness will be the most useful single determinant for this decision. Weiss et al. 1994 concluded that N0 necks should be treated electively when the occult metastatic rate is more than $20 \%[15]$.

In 61/327 patients lymph node involvement was demonstrated. Studies have shown that a significant number of patients with early oral cavity cancers who are observed will develop neck recurrence and many of these recurrences will be of advanced stage with poor prognostic factors such as extra-capsular spread (ECS) [13]. The salvage rates in these patients with recurrences were found to be only $30 \%$ [12]. However we must bear in mind that there are no available randomised controlled trials comparing prophylactic treatment of the $\mathrm{N}_{0}$ neck with observation and therapeutic neck dissection on detection of recurrence. There is a body of evidence from retrospective studies suggesting that in patients who do not have prophylactic therapy of the clinically $\mathrm{N}_{0}$ neck there is often a low salvage rate on disease recurrence [16].

The diagnosis and treatment of oral cancer are negative predictors of health-related quality of life. In the oral cavity both, a "wait and see" policy or an elective selective neck dissection may be successful approaches tailored to specific patients. The reality is that some patients with oral cancer and $\mathrm{N}_{0}$ neck do not have occult metastases and would not benefit from an elective neck dissection, some may have micrometastases but there is no certainty that these will necessarily progress. There are a group of patients with occult metastases which do present later after primary treatment and have a poorer outcome than would have been anticipated from their original disease $[9,12]$. Current data has been unable to provide recommendations based on sound evidence. Especially in the clinical negative neck, shown in this study, surprisingly, there is a high rate of occult metastases within the lymph nodes of $18.65 \%$ of patients. In the present study a large amount of patients were included and even higher lymph node metastases rates have been reported up to $42 \%$ in the past $[12,13]$.

\section{Conclusion}

Even though staging of patients is still increasing by better $\mathrm{CT}$ and MRI scanning there is a lack of evidence that patients with negative lymph node staging would benefit from neck preservation. When we assess the literature we must recognize that the poor salvage rates recorded were based on work that was completed in the 80's. Overall as surgeons we may observe the neck more frequently and this may be due to advances in the examination of nodal status and potentially the higher detection rates of patients with early lymph node metastases. Nevertheless, as stated in the guidelines of oral cavity cancer neck dissections should be performed as part of the concept to complete the oncological therapy of this complex tumour entity including its biological behaviour [17].

\section{Competing interests}

The authors declare that they have no competing interests.

\section{Authors' contributions}

TM: conception and design; acquisition of data; drafting and revising the manuscript; DAM: conception and design; acquisition of data; drafting and revising the manuscript. SW: analysis and interpretation of data; drafting and revising the manuscript. LMR: analysis and interpretation of data; drafting and revising the manuscript; KDW: analysis and interpretation of data; drafting and revising the manuscript; AK: conception and design; acquisition of data; drafting and revising the manuscript; All authors read and approved the final manuscript and agree to be accountable for all aspects of the work in ensuring that questions related to the accuracy or integrity of any part of the work are appropriately investigated and resolved.

\section{Acknowledgements}

This research was not funded. None of the authors received any funding for this work.

\section{Author details}

${ }^{1}$ Department of Oral and Maxillofacial Surgery, Technische Universität München, Klinikum Rechts der Isar, Ismaninger Str. 22, 81675 Munich, Germany. ${ }^{2}$ Department of Oral and Maxillofacial Surgery, Oral and Facial Specialties Department, Mid Yorkshire Hospitals NHS Trust, Aberford Road, WF1 4DG West Yorks, UK. ${ }^{3}$ Institute for Medical Biometry, Epidemiology und Medical Informatics (IMBEI), Universitätsklinikum des Saarlandes, Homburg/ Saar, Germany.

Received: 6 January 2014 Accepted: 14 May 2014 Published: 20 May 2014

\section{References}

1. Shah JP, Gil Z: Current concepts in management of oral cancer-surgery. Oral Oncol 2009, 45(4-5):394-401.

2. Shingaki S, Takada M, Sasai K, Bibi R, Kobayashi T, Nomura T, Saito C: Impact of lymph node metastasis on the pattern of failure and survival in oral carcinomas. Am J Surg 2003, 185(3):278-284.

3. Mücke T, Koschinski J, Wagenpfeil S, Wolff KD, Kanatas A, Mitchell DA, Deppe H, Kesting MR: Functional outcome after different oncological interventions in head and neck cancer patients. J Cancer Res Clin Oncol 2012, 138(3):371-376.

4. Bar Ad V, Chalian A: Management of clinically negative neck for the patients with head and neck squamous cell carcinomas in the modern era. Oral Oncol 2008, 44(9):817-822. 
5. Elsheikh MN, Rinaldo A, Ferlito A, Fagan JJ, Suarez C, Lowry J, Paleri V, Khafif A, Olofsson J: Elective supraomohyoid neck dissection for oral cavity squamous cell carcinoma: is dissection of sublevel IIB necessary? Oral Oncol 2008, 44(3):216-219.

6. Mücke T, Wolff KD, Wagenpfeil S, Mitchell DA, Hölzle F: Immediate microsurgical reconstruction after tumor ablation predicts survival among patients with head and neck carcinoma. Ann Surg Oncol 2010, 17(1):287-295.

7. Brown JS, Magennis P, Rogers SN, Cawood Jl, Howell R, Vaughan ED: Trends in head and neck microvascular reconstructive surgery in Liverpool (1992-2001). Br J Oral Maxillofac Surg 2006, 44(5):364-370.

8. Brown JS, Rogers SN, Lowe D: A comparison of tongue and soft palate squamous cell carcinoma treated by primary surgery in terms of survival and quality of life outcomes. Int J Oral Maxillofac Surg 2006, 35(3):208-214.

9. Zhang T, Lubek JE, Salama A, Dyalram D, Liu X, Ord RA: Treatment of CT1NOMO tongue cancer: outcome and prognostic parameters. J Oral Maxillofac Surg 2013, 72(2):406-414.

10. Woolgar JA: Histopathological prognosticators in oral and oropharyngeal squamous cell carcinoma. Oral Oncol 2006, 42(3):229-239.

11. Fakih AR, Rao RS, Patel AR: Prophylactic neck dissection in squamous cell carcinoma of oral tongue: a prospective randomized study. Semin Surg Oncol 1989, 5(5):327-330

12. Ho CM, Lam KH, Wei WI, Lau SK, Lam LK: Occult lymph node metastasis in small oral tongue cancers. Head Neck 1992, 14(5):359-363.

13. Kligerman J, Lima RA, Soares JR, Prado L, Dias FL, Freitas EQ, Olivatto LO: Supraomohyoid neck dissection in the treatment of $\mathrm{T} 1 / \mathrm{T} 2$ squamous cell carcinoma of oral cavity. Am J Surg 1994, 168(5):391-394.

14. Yuen AP, Ho CM, Chow TL, Tang LC, Cheung WY, Ng RW, Wei WI, Kong CK, Book KS, Yuen WC, Trendell-Smith NJ, Chan YW, Wong BY, Li GK, Ho AC, Womg SY, Yao TJ: Prospective randomized study of selective neck dissection versus observation for NO neck of early tongue carcinoma. Head Neck 2009, 31(6):765-772.

15. Weiss MH, Harrison LB, Isaacs RS: Use of decision analysis in planning a management strategy for the stage No neck. Arch Otolaryngol Head Neck Surg 1994, 120(7):699-702.

16. Leon X, Quer M, Orus C, Sancho FJ, Bague S, Burgues J: Selective dissection of levels II-III with intraoperative control of the upper and middle jugular nodes: a therapeutic option for the NO neck. Head Neck 2001, 23(6):441-446.

17. Wolff KD, Follmann M, Nast A: The diagnosis and treatment of oral cavity cancer. Dtsch Arztebl Int 2012, 109(48):829-835.

\section{doi:10.1186/1471-2407-14-346}

Cite this article as: Mücke et al:: Incidence and outcome for patients with occult lymph node involvement in $\mathrm{T} 1$ and $\mathrm{T} 2$ oral squamous cell carcinoma: a prospective study. BMC Cancer 2014 14:346.

\section{Submit your next manuscript to BioMed Central and take full advantage of:}

- Convenient online submission

- Thorough peer review

- No space constraints or color figure charges

- Immediate publication on acceptance

- Inclusion in PubMed, CAS, Scopus and Google Scholar

- Research which is freely available for redistribution

Submit your manuscript at www.biomedcentral.com/submit 